\title{
ALLELOPATHIC EFFECTS OF PAPAVER SOMNIFERUM ON GERMINATION AND INITIAL SEEDLING GROWTH OF ECHINOCHLOA CRUSS-GALLI
}

\begin{abstract}
Muhammad Ather Nadeem ${ }^{1}$, Bilal Ahmad Khan ${ }^{1 *}$ Sadia Afzal ${ }^{2}$, Rizwan Maqbool ${ }^{3}$, Hasnain Waheed ${ }^{1}$, Aneela Nijabat ${ }^{4}$, Muhammad Ikram $^{5}$, Amir Aziz ${ }^{6}$, Muhammad Adnan $^{1}$, Qaisar Mehmood7, Hasnain Umer ${ }^{3}$
\end{abstract}

DOI: https://doi.org/10.28941/pjwsr.v27i2.951

\begin{abstract}
Weeds are unwanted plants in crop that can be controlled by different methods among them use of aqueous extracts of crops is an imperative method. In this method allelochemicals present in crop plant help in suppressing or inhibiting weeds. Therefore, this study was planned to investigate the allopathic potential of aqueous extract of winter crop Papaver somniferum (opium) on summer weed Echinochloa cruss-galli (barnyard grass. The experiment comprised of seven concentrations $(0,0.25,0.50,1,2,4$, and $8 \%)$ of different plant parts i.e., leaves, stem and flower of P. somniferumwere. All the tested concentrations and plant parts of $P$. somniferum significantly reduced mean emergence time, germination index, germination percentage, time to $50 \%$ germination as well as well growth of E. crussgalli weed. However, maximum mean emergence time (9.07 days), time to $50 \%$ germination (3.67 days) was noted by applying leaves and stem extract, respectively. Application of aqueous extract of stem at $8 \%$ concentration resulted in greatest time to complete $50 \%$ germination (5.42 days) and lowest fresh weight $(6.28 \mathrm{~g})$, dry weight (1.00 g) and root length $(0.33 \mathrm{~cm})$ of E. cruss-galli. Whereas leaf extract at $8 \%$ concentration produces less shoot length $(1.13 \mathrm{~cm})$ and more emergence time (9.18 days). Lowest emergence percentage $(6.67 \%)$ and germination index $(0.89)$ were produced by aqueous extract of fruit at $8 \%$ concentration. On the basis of this experiment, it can be concluded that higher concentration ( $8 \%$ ) of stem extract of $\mathrm{P}$. somniferum was used to biologically control the infestation of E. cruss-galli weed.
\end{abstract}

Keywords: Allelopathic effect, seedling growth, Echinochloa cruss-galli, Papaver somnifrum

Citation: Nadeem, M.A., B.A. Khan, S. Afzal, R. Maqbool, H. Waheed, A. Nijabat, M. Ikram, A. Aziz, M. Adnan, Q. Mehmood, H. Umer, 2021. Allelopathic effects of Papaver somniferum on germination and initial seedling growth of Echinochloa cruss-galli. Pak. J. Weed Sci.

Res.,27 (2):239-252.

${ }^{1}$ Department of Agronomy, College of Agriculture, University of Sargodha-40100 Pakistan.

${ }^{2}$ Department of Botany, University of Agriculture, Faisalabad-3800, Pakistan.

${ }^{3}$ Department of Agronomy, University of Agriculture, Faisalabad-3800, Pakistan.

${ }^{4}$ Department of Botany, University of Sargodha-40100, Pakistan

${ }^{5}$ Department of Botany, PMAS Arid Agriculture University, Rawalpindi-46300, Pakistan.

6Department of Soil \& Environmental Sciences, College of Agriculture, University of Sargodha-40100 Pakistan.

${ }^{7}$ Department of Agricultural Sciences, The University of Haripur, Pakistan

Correspondence:* Bilal Ahmad Khan (bilalahmadkhan678@gmail.com) 



\section{Introduction}

Weeds are unwanted plants in crops that compete with crop for water, nutrients, place and sunlight for growth that resulted in poor yield and quality of crop (Gallandt and Weiner, 2001). In Pakistan average loss due to weed in different crops are 20 to $30 \%$ (Shad, 1987). In cereal crops, the losses due to weed infestations are approximately 30, 40,4 and 5 billion rupees for wheat, rice, maize and gram, respectively (Anonymous, 2005; Nadeem et al., 2021). So, it is necessary to control the weeds to reduce the competition and enhance the crop yield (Macias et al., 2002; Nadeem et al., 2020). In modern agriculture production system weeds can be controlled efficiently with the use of chemical herbicides (Bajwa, 2014). Use of chemical for effective weed control results in low quality of product, weed resistance, environmental pollution (Macias et al., 2002; Nadeem et al., 2020b). Different methods are used to control weeds such as biological, chemical, mechanical, and cultural control (Melander et al.,2005). Extreme and continuous use of herbicides has resulted in resilient weed populations and this phenomenon urged upon the misuse of allelopathic possible of crop plants (Ferreira and Reinhardt, 2010). Allelochemicals could be used as tool for controlling weeds (Nadeem et al., 2020a; Nadeem et al., 2020b; Jabran et al., 2015). Allelopathic crops have potential to inhibit the growth of weeds (Chung et al., 2006).

Opium (Papaver somniferum) is a medicinal plant and many researchers reported that opium has allelopathic potential (Labanca et al., 2018). Opium crop release different allelochemicals at maturity which have potential to control weeds in different crops (Nadeem et al., 2020a). The grassy plant had herbicidal potential on the parthenium weed (Anjum et al., 2005; Javaidet al., 2005). Kadioglu et al., (2005) and Nadeem et al., (2020b) depicted that germination, shoot and root length and dry weight of different crop species inhibited with foliar application of water extract of weeds. Water extract of weeds might have inhibitory or promotry effect on germination and seedling growth (Alam and Islam, 2002). Different plants have different potential on target weed or crop plant. Water extract of wild onion leaves produced inhibitory effect on germination and crop seedling growth (Baber et al., 2009). Opium is most important dominant and competitive broad-leaves weed in winter cereals (Ravlić et al., 2012). Allelopathic effect of opium on germination capacity of cereals, also indicated that water extracts from fresh plant parts of opium significantly reduced germination of both wheat and barley (Ravlić et al., 2012). By blocking nutrient reserve hydrolysis, allelochemicals inhibit germination of seed (Ghodake et al., 2012).

The mixture of allelochemical with low dose of herbicide can be used for effective weed control (Bhowmik, 2003). Cheema et al. (2000) directed that the dose of herbicide in cotton is reduced to $5-60 \%$ while applied with sorghum extract (with rate of $12 \mathrm{~L} \mathrm{ha}^{-1}$ ). Crop plants for example opium (Papaver somniferum.) sunflower (Helianthus annuus), eucalyptus (Eucalyptus camaldulensis) and other species had allelopathic effects against weed growth (Skrzypek et al.., 2015). It is needed to examine the phytotoxic effects of opium (Papaver somniferum) (opium) water extracts on $E$. cruss-galli. To control weeds there are many alternative strategies such as non-chemical control by using aqueous extracts (bio herbicides) of weed plants (Cirujeda et al., 2008). Bio herbicides have the potential to create friendly eco-products for weed management and are easily biodegradable than synthesized herbicides (Nadeem et al., 2021; Nadeem et al., 2020c; Ghafarbi et al., 2012). Water extract of opium is natural and has no chemical hazards on target crop and helpful to control weeds and increase the productivity of crop. The present study was carried-out to explore the allelopathic effect of water extracts of the opium plant parts such as stem, leaves and flower to control the 
germination and seedling growth of $E$. cruss-galli weed specifically.

\section{Materials and Methods}

The experiment was carried out in the weed science laboratory at Department of Agronomy, University of Agriculture Faisalabad. The objective of this study was to check allelopathic effects of aqueous extracts of winter crop Papavare somniferum (opium) on summer weed Echinochloa cruss-galli the experiment was arranged in factorial under CRD with three replications and seven treatments.

\section{Collection of plant parts}

To make aqueous extract of $P$. somniferum (opium) plants were collected from weed bank of Agronomy Farm, University of Agriculture Faisalabad. To make aqueous extract plants of $P$. somniferum (opium) were harvested above the ground surface at maturity and dried for two weeks at ambient temperature. After drying properly different parts of plants were separated and chopped into $2 \mathrm{~cm}$ pieces for extract formation.

\section{Preparation of aqueous extracts}

Plant aqueous extracts of different parts of $P$. somniferum (opium) were made by adding $10 \mathrm{~g}$ of chopped dried plant material into $100 \mathrm{ml}$ of distilled water in bottles separately with $1: 10 \mathrm{w} / \mathrm{v}$ ratio. Plant material were soaked in water for at least 24 hours at room temperature. These aqueous extracts were made from each desired part of opium such as leaves, stem, fruit, flower etc. then the decanted material was passed through a cotton cloth to attain the water extracts of different parts of $P$. somniferum (opium). That process gave $10 \%$ extract, from this $67.2 \mathrm{ml}$ extract were added in $16.8 \mathrm{ml}$ distilled water due to this the final volume was $84 \mathrm{ml}$ that was act as stock solution. From this stock solution we made further dilutions that are $(0.25 \%, 0.5 \%, 1 \%, 2 \%$, $4 \%$ and $8 \%$ ). These dilutions were made by using the following equation.

$\mathrm{C}_{1} \mathrm{~V}_{1}=\mathrm{C}_{2} \mathrm{~V}_{2}$

Each dilution has $42 \mathrm{ml}$ total volume. Each dilution of each extract placed in separate bottles and then tagged these bottles by name of each dilution with its plant name too carefully for their easy utilization in next procedure.

\section{Laboratory Experiment}

In laboratory experiment the aqueous extracts of $P$. somniferum (opium) different parts such as leave, stem, fruit and flower were used on summer weed E. cruss-gall. The experiment was conducted in each $9 \mathrm{~cm}$ petri plates. Filter papers were used as a sowing medium. To check the allelopathic effect 21 treatment combinations of $P$. somniferum (opium) were applied on $E$. cruss-gall. Each petri plate contains five seed of $E$. cruss-gall. Whatman filter papers No 1placed in each petri plate before adding the seed on it. Then $7 \mathrm{ml}$ of all opium extracts dilutions of each part i.e., leaves, stem, flower and fruit were added in all the petri plates having 3 replications for each dilution. One treatment was kept as control and moist with distilled water. Then to reduce the excess of evaporation petri plates were covered and rapped with parafilm. The petri plates were kept at $30^{\circ} \mathrm{C}$ temperature and treatments were again moistened after one week. The experiment was laid out under completely randomized design with factorial arrangement. The experiment consist of different concentration of water extracts $0.0 \%$, $0.25 \%, 0.5 \%, 1 \%, 2 \%, 4 \%, 8 \%$ and Plant parts of Papaver somniferum (opium) (Leaves, Stem, Flower).

\section{Observation:}

The data regarding germination of seeds were recorded every day for 14 days. After the 14 days, harvest the germinated seedlings of $E$. cruss-gall observed the different parameters like shoot and root length, fresh and dry weight. Fresh weight was recorded immediately after harvesting while dry weight seedlings were observed after drying in oven for two days at $60{ }^{\circ} \mathrm{C}$.

Mean Emergence Time (MET)

It was examined by using equation of Ellis and Reborts (1981).

$$
M E T=\frac{\sum(D n)}{\sum n}
$$




\section{Germination index of Echinochloa cruss-galli}

Germination index was observed as per association of official seed analysis (1983) by using formula

$$
\begin{array}{r}
G I=\frac{\text { No.of germinated seeds }}{\text { Days of first count }}+--- \\
-+\frac{\text { No. of germinated seeds }}{\text { Days of final count }}
\end{array}
$$

Emergence percentage of $E$. crussgalli(\%)

Germinated number of seeds was counted daily up to 14 days after which germination ceased. The germination \% was calculated by using following formula.

Germination percentage

\section{Time to $50 \%$ germination of \\ Echinochloa cruss-galli} $=\frac{\text { No. of germinated seeds }}{\text { Total No. of seeds }}$ $\times 100$

The time to obtain 50\% emergence or germination $\left(E_{50}\right.$ or $\left.T_{50}\right)$ was calculated according to the following formula of Coolbear et al. (1984)

$$
T \mathbf{5 0}=t i+\left[\frac{\frac{N}{2}-n i}{n j-n i}\right](t j-t i)
$$

\section{Growth attributes of Echinochloa cruss-galli}

All seedlings from each petri plate were separate 14 days after germination. After that shoot and root length was calculated by using meter rod from base level to top of the plants. Fresh weight of seedlings was examined by separating seedlings from petri dish and measuring by using digital weight balance. Seedlings dry weight was observed by oven drying the seedlings for 48 hours at $60^{\circ} \mathrm{C}$ then weighted to get average dry weight of seedling by using digital balance.

\section{Statistical analysis:}

Collected data were analyzed by using the Statistics software (version, 8.1Statistix, Tallahassee, FL, USA) and least significant difference (LSD) test was used to compare the means at 5\% probability level. Microsoft office 2010 was used to draw figures using standard error ( \pm SE).

\section{Results and Discussions \\ Mean Emergence Time of Echinochloa cruss-galli}

Aqueous extract of $P$. somniferum

had significant impact on mean emergence time of $E$. cruss-galli seedlings (Table 1). All the plant parts significantly delayed mean germination time of barnyard grass seedlings. Leaves extract of $P$. somniferum exhibited maximum mean emergence time (9.07 days) of weed while in fruit extract minimum mean emergence time (3.45 days) was noted.The impact of extracts concentration on mean emergence time on $E$. cruss-galli seedlings was nosignificant. Interaction effect of concentration and extract interaction was significantly different according to mean emergence time of $E$. cruss-galli seedlings. Highest value of mean emergence time (9.18 days) was given with higher concentration $(8 \%)$ of leaves and lower concentration $(0.25 \%)$ of fruit gave the lower mean emergence time (3.10 days). A significantly inhibitory effect of water extracts of $E$. hirta with different concentration on groundnut mean emergence time was exposed (Rose and Anitha, 2012).

\section{Germination Index of Echinochloa cruss-galli}

The different concentrations of aqueous extracts of $P$. somniferum affected germination index of $E$. crussgalli seedlings significantly. Lowest value of germination index (3.96) was observed at $8 \%$ and the highest value of germination index (5.49) was observed in control $0 \%$. There was significant difference among different plant parts of $P$. somniferumin which fruit showed the inhibitory effects. While the leaves showed the promontory effects. Stem also showed somewhat inhibitory effects. Interaction effects of parts and concentration of $P$. somniferum aqueous extract was found significant. Higher values of germination index (9.15) at $4 \%$ was obtained by leaves, while lower value of germination index (0.89) at $1 \%$ was obtained by fruit. Same findings were attained by Khan et al. (2011) performing an experiment to 
observe effect of $S$. marianum aqueous extracts onC. arietinum, $V$. radiata, $P$. vulgaris and Glycine max germination. Effect of extracts on test species was significant which reduced the germination index as compared to control and inhibitory effect was increased by enhancing the extracts concentration.

\section{Emergence Percentage of Echinochloa cruss-galli (\%)}

Influence of water extracts of different plant part (stem, fruit and leaves) of $P$. somniferum on emergence percentage of $E$. cruss-galli seedlings was significantly different (Table 3). Fruit extracts inhibited the emergence percentage of $E$. cruss-galli seedlings in comparison to leaves and stem. Maximum germination percentage $(88.57 \%)$ was calculated for leaves. And minimum value $(63.81 \%)$ was calculated fruit extract application. A significant difference found in emergence percentage of $E$. cruss-galli by the action of aqueous extracts concentrations. Higher emergence percentage $(93.3 \%)$ was observed at control $0 \%$. While the lowest values of emergence percentage (48.89) were showed by $8 \%$ concentration. Interaction influence of different concentrations and plant parts was observed significantly different. Fruit gave the inhibitory effect for emergence percentage while the leave showed the stimulatory emergence percentage the stem gave somewhat low dose response. Fruit also gave low dose response up to $0.5 \%$ concentration. Takao et al. (2011) performed atrial to observeimpact of Ipomoea cairica aqueous extract on E. cruss-galli, Bidens Pilosa, I. grandifolia and $E$. heterophylla. Outcomesdepicted that the test species showed a significant inhibitory response on emergence percentage. As compared to lower concentrations, higher extract concentrations effectively reduced the emergence percentage. Nadeem et al., 2020c reported that the different concentration of aqueous extracts $P$. somniferum produce significant influence on emergence percentage of $O$. punctata (red rice), highest concentration (8\%) significantly reduced emergence of red rice $(48.89 \%)$ while $0 \%$ concentration result in maximum emergence of red rice $(93.33 \%)$.

\section{Time to $50 \%$ Germination of Echinochloa cruss-galli}

Allelopathic influence exerted by different plant parts of opium on time to $50 \%$ germination of E. cruss-galli seedlings was found significant (Table 5 ). Leaves gave the lowest time (2.81 days) to $50 \%$ germination values while stem extract take more time (3.67 days) to complete $50 \%$ germination. Different concentrations of extracts of opium have significant effects on time to $50 \%$ germination of $E$. cruss-galli seedlings. Maximum valueof time to $50 \%$ germination (3.56 days) was showed by $2 \%$ concentration and minimum value of time to $50 \%$ germination (2.74 days) was given by $0.25 \%$ concentration. Interaction of different plant parts and concentration on time to $50 \%$ concentration was observed significant. Leaves gave the inhibitory effect at all concentrations but the lowest value of time to $50 \%$ germination at $4-8 \%$ concentration. The stem gave the stimulatory effect and it showed the highest time to $50 \%$ germination at $8 \%$ concentration. Fruit showed the low dose response up to $0.5 \%$ concentration. Similar results were observed as, allelopathic influence of $R$. dentatus aqueous extracts was shown effective in enhancing the time to $50 \%$ germination of Helianthus annus and $T$. aestivum seedlings. With the use of extract of $R$. dentatus, an increment in time to $50 \%$ germination was observed at higher concentration as compare to control (Anjum \& Bajwa, 2005).

\section{Shoot length of Echinochloa cruss- galli (cm)}

Aqueous extracts of $P$. somniferum (opium) different plant parts had significant influence on shoot length of $E$. cruss-galli (Table 5). The lowest value of shoot length $(2.82 \mathrm{~cm})$ was recorded among different plant parts with the aqueous extracts of stem of opium whereas, longest shoot lengths $(3.42 \mathrm{~cm})$ were noted with application of leaves aqueous extracts of $P$. somniferum. The 
interaction among different concentration and plant parts was also significant. It is recorded that the concentration which was kept as control gave the longest shoots that might be statically similar with the leaf extract application at the concentration of $0.25 \%$. The fruit extract of opium had stimulatory influence on the shoot length of E. cruss-galli at lower concentrations at $2.00 \%$ concentration. Whereas, leaf demonstrated low-dose response at $0.25 \%$ other than this value or concentration all other values of concentrations of leave reduced the shoot length of $E$. cruss-galli. Among different concentration highest shoot length (5.10 $\mathrm{cm})$ was examined under control $(0 \%)$ whereas, lowest shoot length $(1.510 \mathrm{~cm})$ at higher concentration ( $8 \%$ ). The delayed germination and slow growth of seedlings can be attributed to the reduction in shoot length. The allelochemicals of opium aqueous extracts at lower concentration of different plant parts might be act as hormones for $E$. cruss-galli to enhance its growth. The lower concentrations hormetic influence of aqueous extracts of different plant parts as they act as hormones for plant growth has also been described by (Cheema et al., 2003). Instead of $0.25 \%$ concentration, at all other concentrations, the extracts of leaves indicate the inhibitory effect. The shoot length was suppressed by inhibitory influence of opium water extracts has also been reported by the verdicts of (Khaliq et al., 2009). Nadeem et al., 2020a revealed that $2 \%$ concentration with fruit extract of C. tinctorius produced the longest (7.91 $\mathrm{cm}$ ) shoot length of $O$. punctata. The higher concentration ( $8 \%$ ) with aqueous extracts of $\mathrm{C}$. tinctorius leaves gave the lowest $(4.51 \mathrm{~cm})$ shoot length of $O$. punctata.

\section{Root length of Echinochloa cruss-galli (cm)}

Effect of different plant partsextract of $P$. somniferum (opium) on root length of $E$. cruss-galli was significantly different. The lowest value of root length $(0.63 \mathrm{~cm})$ was recorded among different plant parts with the aqueous extracts of fruit of opium whereas, longest root lengths $(1.29 \mathrm{~cm})$ were noted with application of leaves aqueous extracts of $P$. somniferum. The interaction among different concentration and plant parts was non-significant. It is recorded that the concentration which was kept as control gave the longest roots that might be statically similar with the stem extract application at the concentration of $0.25 \%$. The leaf extract of opium had stimulatory influence on the root length of E. cruss-galliat lower concentrations at $2.00 \%$ concentration. The stem and fruit extracts gave the stimulatory influence at lower extract concentrations. The lower concentration application of stem extracts caused in significantly higher concentration associated with control. While, the fruit extract application enhanced the root length up to the concentration of $0.25 \%$ also at $4.00 \%$. Among different concentration longest root length $(1.63 \mathrm{~cm})$ was recorded at and shortest $(0.75 \mathrm{~cm})$ by $8 \%$. The allelochemicals of opium aqueous extracts at lower concentration of different plant parts might be act as hormones for $E$. cruss-galli to enhance its growth. The lower concentrations hormeotic influence of aqueous extracts of different plant parts as they act as hormones for plant growth has also been described by (Cheemaet al.,2003). Nadeem et al., 2020d depicted that among the various concentrations of $\mathrm{S}$. oleraceus maximum $(1.63 \mathrm{~cm})$ and minimum $(0.44 \mathrm{~cm})$ root length of $\mathrm{E}$. cruss-galli was examined at $1 \%$ and $8 \%$ concentrations, respectively. Nadeem et al., 2021 reported that among different concentrations of weeds extracts of S. oleraceus, the highest length of root of 0 . punctata $(4.83 \mathrm{~cm})$ was examined at concentration $1 \%$ while lowest length of root $(3.94 \mathrm{~cm})$ was recorded at concentration $0.25 \%$.

\section{Fresh weight of Echinochloa cruss- galli (g)}

Aqueous extract of Papaver somniferum (opium) had significant influence on fresh weight of $E$. cruss-galli. Lowest values of fresh weight $(10.35 \mathrm{~g})$ were recorded among different plant parts with the aqueous extracts of stem of 
opium because of reduced growth of barnyard grass seedlings whereas, higher values of fresh weight $(16.93 \mathrm{~g})$ were noted with application of leaves aqueous extracts of $P$. somniferum. The interaction among different concentrations and plant parts was non-significant. The lowest fresh weight $(11.06 \mathrm{~g})$ was examined under fruit extract at $1 \%$ concentration while highest fresh weight $(22.50 \mathrm{~g})$ at $0.25 \%$ concentration by leaves extract.The fruit and stem extracts gave the stimulatory influence at lower extract concentrations. The lower concentration application of stem extracts caused in significantly higher concentration associated with control. While, due to the fruit extract application it enhanced the fresh weight values up to the concentration of $0.5 \%$. Different concentration of aqueous extract of $P$. somniferum significantly influence on fresh weight of weed. Maximum fresh weight $(15.91 \mathrm{~g})$ under control $(0 \%)$ whereas minimum $(12.28 \mathrm{~g})$ by $8 \%$ concentration. The lower concentration of aqueous extract of opium allelochemicals might be act as hormones for barnyard grass to enhance its growth as the growth of seedlings were enhanced seedlings weight also increased. The delayed germination and slow growth of seedlings can be attributed to the reduction in fresh weight. The significant modifications were detected between water extract of different plant parts concerning fresh weight. The lower concentrations hormeotic influence of aqueous extracts of different plant parts as they act as hormones for seedlings growth has also been described by (Cheema et al., 2003). At all concentration, the extracts of stem indicate the inhibitory effect. As, seedlings growth was inhibited by the inhibitory influence of opium water extracts, fresh weight also reduced has also been reported by the verdicts of (Khaliq et al., 2009).

Dry weight of Echinochloa cruss-galli (g)

The aqueous extracts of $P$. somniferum (opium) had statistically non-significant influence on the dry weight of $E$. cruss- galli (barnyard grass). The lowest values of dry weight $(3.18 \mathrm{~g})$ were recorded among different plant parts with the aqueous extracts of fruit of opium because of reduced growth of barnyard grass seedlings whereas, higher values of dry weight $(4.43 \mathrm{~g})$ were noted with application of leaves aqueous extracts of $P$. somniferum. The interaction among different concentrations and plant parts was also found non-significant. Highest dry weight $(8.17 \mathrm{~g})$ was observed under stem extract at $0.25 \%$ while lowest dry weight $(1.00 \mathrm{~g})$ at $8 \%$ by stem extract. The leaves and stem extracts gave the stimulatory influence at lower extract concentrations. The lower concentration application of stem extracts caused in significantly higher concentration associated with control. While, due to the leaves extract application it enhanced the dry weight values up to the concentration of $0.5 \%$. Among different concentration maximum dry weight $(5.55 \mathrm{~g})$ under control $(0 \%)$ whereas minimum $(1.52 \mathrm{~g})$ at $8 \%$ concentration. The leaves and stem showed the stimulatory effect at low concentrations. Might have been due to hormeotic effect the dry weight enhanced because at lower concentrations seedlings were grow too efficiently. The lower concentration of aqueous extract of different plant parts of opium allelochemicals might be act as hormones for barnyard grass to enhance its growth as the growth of seedlings were enhanced seedlings weight also increased. At all concentration, extracts of stem indicate the inhibitory effect. As, seedlings growth was inhibited by the inhibitory influence of opium water extracts, dry weight also reduced has also been reported by the verdicts of (Khaliq et al., 2009). The delayed germination and slow growth of seedlings can be ascribed to the reduction in dry weight. Nadeem et al., 2020a coniform that at $0.25 \%$ concentration with leaf extract of $\mathrm{C}$. tinctorius produced the least $(0.80 \mathrm{~g})$ dry weight of 0 . punctata. Nadeem et al., 2021 Different concentration of water extracts of $S$. oleraceus produced significant influence on fresh weight of red rice. Seedlings with 
highest fresh weight (114.94 mg) were recorded at $0.25 \%$ concentration, while lowest fresh weight of seedlings $(74.37 \mathrm{~g})$ at $8 \%$ concentration of aqueous extracts of S. oleraceus.

\section{Conclusion:}

On the bases of this experiment, it was concluded that higher concentration $(8 \%)$ with stem extract of $P$. somniferum was used to biologically control the infestation of $E$. cruss-galli weed

Table 1: Mean emergence time of $E$. cruss-galli as influenced by different concentration of different plant parts of $P$. somniferum aqueous extracts

\begin{tabular}{ccccccccc}
\hline & \multicolumn{7}{c}{ Concentration (MET) } \\
\cline { 2 - 8 } Leaf & $\mathbf{0 \%}$ & $\mathbf{0 . 2 5 \%}$ & $\mathbf{0 . 5 \%}$ & $\mathbf{1 \%}$ & $\mathbf{2 \%}$ & $\mathbf{4 \%}$ & $\mathbf{8 \%}$ & Mean \\
\cline { 2 - 8 } Stem & $9.07 \mathrm{a}$ & $8.96 \mathrm{a}$ & $9.09 \mathrm{a}$ & $9.16 \mathrm{a}$ & $9.06 \mathrm{a}$ & $8.90 \mathrm{a}$ & $9.18 \mathrm{a}$ & $9.07 \mathrm{a}$ \\
Fruit & $3.70 \mathrm{de}$ & $3.87 \mathrm{cde}$ & $3.87 \mathrm{cde}$ & $4.26 \mathrm{~cd}$ & $3.83 \mathrm{cde}$ & $4.31 \mathrm{~cd}$ & $5.91 \mathrm{~b}$ & $4.25 \mathrm{~b}$ \\
Mean & $5.51 \mathrm{cde}$ & $3.10 \mathrm{def}$ & $3.62 \mathrm{cde}$ & $2.78 \mathrm{ef}$ & $4.78 \mathrm{bc}$ & $4.48 \mathrm{bc}$ & $1.67 \mathrm{f}$ & $3.45 \mathrm{c}$ \\
& & $5.31 \mathrm{a}$ & $5.53 \mathrm{a}$ & $5.40 \mathrm{a}$ & $5.93 \mathrm{a}$ & $5.89 \mathrm{a}$ & $5.54 \mathrm{a}$ & \\
\hline
\end{tabular}

Table 2: Germination index of $E$. cruss-galli as influenced by different concentration of different plant parts of $P$. somniferum aqueous extracts

Plant Parts

Concentration (GI)

\begin{tabular}{lcccccccc} 
& \multicolumn{1}{c}{$\mathbf{0 \%}$} & $\mathbf{0 . 2 5 \%}$ & $\mathbf{0 . 5 \%}$ & $\mathbf{1 \%}$ & $\mathbf{2 \%}$ & $\mathbf{4 \%}$ & $\mathbf{8 \%}$ & Mean \\
\cline { 2 - 8 } Leaf & $8.21 a b$ & $7.17 a b$ & $7.19 a b$ & $6.86 b$ & $6.85 b$ & $9.15 a$ & $8.65 a b$ & $7.72 a$ \\
Stem & $3.97 c$ & $3.16 c$ & $4.14 c$ & $3.97 c$ & $3.31 c$ & $2.56 c d e$ & $2.34 c d$ & $3.35 b$ \\
Fruit & $4.30 c$ & $3.11 c d$ & $3.56 c$ & $0.89 \mathrm{e}$ & $2.14 c d e$ & $0.94 d e$ & $0.92 c$ & $2.27 c$ \\
Mean & $5.49 a$ & $4.48 a b$ & $4.96 a b$ & $3.90 b$ & $4.11 b$ & $4.22 a b$ & $3.96 b$ & \\
\hline
\end{tabular}

Table 3: Emergence percentage (\%) of $E$. cruss-galli as influenced by different concentration of different plant parts of $P$. somniferum aqueous extracts

\begin{tabular}{ccccccccc}
\hline Plant Parts & \multicolumn{7}{c}{ Concentration (EP) } \\
\cline { 2 - 9 } Leaf & $\mathbf{0 \%}$ & $\mathbf{0 . 2 5 \%}$ & $\mathbf{0 . 5 \%}$ & $\mathbf{1 \%}$ & $\mathbf{2 \%}$ & $\mathbf{4 \%}$ & $\mathbf{8 \%}$ & Mean \\
\cline { 2 - 9 } & $86.67 a$ & $93.33 a b$ & $80.00 a b c$ & $73.33 a b c$ & $86.67 a$ & 100.00 & 100.00 & 88.57 \\
Stem & $93.33 a b$ & $86.67 a b$ & 100.00 & $100.00 a$ & $93.33 a b$ & $93.33 a$ & $40.00 \mathrm{e}$ & 86.66 \\
Fruit & $100.00 a$ & $86.67 a b$ & $86.67 a$ & $53.33 c d e$ & $66.67 b c d$ & $46.67 d$ & $6.67 f$ & 63.81 \\
Mean & $93.3 a$ & $88.88 a b$ & $88.88 a$ & $75.56 b$ & $82.22 a b$ & $80.00 a$ & $48.89 c$ &
\end{tabular}

Table 4: Time to $50 \%$ germination of $E$. cruss-galli as influenced by different concentration of different plant parts of $P$. somniferum aqueous extracts 


\begin{tabular}{ccccccccc}
\hline Plant Parts & \multicolumn{7}{c}{ Concentration ( $\mathbf{5 0}$} \\
\cline { 2 - 8 } Leaf & $\mathbf{0 \%}$ & $\mathbf{0 . 2 5 \%}$ & $\mathbf{0 . 5 \%}$ & $\mathbf{1 \%}$ & $\mathbf{2 \%}$ & $\mathbf{4 \%}$ & $\mathbf{8 \%}$ & Mean \\
\cline { 2 - 8 } Stem & $2.83 \mathrm{bcd}$ & $2.67 \mathrm{bcd}$ & $2.75 \mathrm{bcd}$ & $3.17 \mathrm{bc}$ & $3.25 \mathrm{bc}$ & $2.50 \mathrm{~cd}$ & $2.50 \mathrm{~cd}$ & $2.81 \mathrm{~b}$ \\
Fruit & $3.06 \mathrm{bc}$ & $3.25 \mathrm{bc}$ & $3.17 \mathrm{bc}$ & $3.50 \mathrm{bc}$ & $3.42 \mathrm{bc}$ & $3.92 \mathrm{~b}$ & $5.42 \mathrm{a}$ & $3.67 \mathrm{a}$ \\
Mean & $3.08 \mathrm{bc}$ & $2.31 \mathrm{~cd}$ & $3.00 \mathrm{bc}$ & $2.33 \mathrm{~cd}$ & $4.00 \mathrm{~b}$ & $3.42 \mathrm{bc}$ & $1.50 \mathrm{~d}$ & $2.81 \mathrm{~b}$ \\
\hline
\end{tabular}

Table 5: Shoot length of $E$. cruss-galli as influenced by different concentration of different plant parts of $P$. somniferum aqueous extracts

\begin{tabular}{|c|c|c|c|c|c|c|c|c|}
\hline \multirow[t]{2}{*}{ Plant Parts } & \multicolumn{8}{|c|}{ Concentration (SL) } \\
\hline & $0 \%$ & $0.25 \%$ & $0.5 \%$ & $1 \%$ & $2 \%$ & $4 \%$ & $8 \%$ & Mean \\
\hline Leaf & $6.01 a$ & $7.88 a$ & $4.74 b$ & $4.02 b$ & $3.11 b c$ & $2.87 \mathrm{bcd}$ & $1.13 \mathrm{e}$ & $3.43 a$ \\
\hline Stem & $3.86 b$ & $4.03 b$ & $3.45 b$ & $2.76 \mathrm{bcde}$ & $2.98 \mathrm{bc}$ & $2.39 \mathrm{cde}$ & $2.12 \mathrm{~cd}$ & $2.82 \mathrm{a}$ \\
\hline Fruit & $5.45 a$ & $5.67 a$ & $4.61 b$ & $2.28 \mathrm{cde}$ & $3.63 b c$ & $2.05 \mathrm{cde}$ & $1.28 \mathrm{de}$ & $2.94 a$ \\
\hline Mean & $5.10 \mathrm{a}$ & $5.86 a$ & $4.27 a$ & $3.02 b$ & $3.24 b$ & $2.44 b c$ & $1.51 \mathrm{c}$ & \\
\hline \multicolumn{9}{|c|}{$\begin{array}{l}\text { Table 6: Root length of } E \text {. cruss-galli as influenced by different concentration of } \\
\text { different plant parts of } P \text {. somniferum aqueous extracts }\end{array}$} \\
\hline \multirow[t]{2}{*}{ Plant Parts } & \multicolumn{8}{|c|}{ Concentration (RL) } \\
\hline & $0 \%$ & $0.25 \%$ & $0.5 \%$ & $1 \%$ & $2 \%$ & $4 \%$ & $8 \%$ & Mean \\
\hline Leaf & $1.63 a$ & $1.80 a$ & $1.25 a$ & $1.62 a$ & $1.42 \mathrm{ab}$ & $1.03 \mathrm{bc}$ & $0.77 \mathrm{~cd}$ & $1.29 a$ \\
\hline Stem & $1.41 \mathrm{ab}$ & $1.40 a b$ & $1.30 \mathrm{a}$ & $0.83 c d$ & $0.45 \mathrm{~cd}$ & $0.34 d$ & $0.33 d$ & $0.91 b$ \\
\hline Fruit & $1.47 a b$ & $1.68 a$ & $1.20 \mathrm{~b}$ & $0.80 \mathrm{~cd}$ & $0.71 \mathrm{~cd}$ & $0.84 \mathrm{~cd}$ & $0.72 \mathrm{~cd}$ & $0.63 b$ \\
\hline Mean & $1.51 \mathrm{a}$ & $1.63 a$ & $1.25 a$ & $1.08 \mathrm{~b}$ & $0.86 \mathrm{bc}$ & $0.75 b c$ & $0.61 c$ & \\
\hline
\end{tabular}

Table 7: Fresh weight of $E$. cruss-galli as influenced by different concentration of different plant parts of $P$. somniferum aqueous extracts

\begin{tabular}{ccccccccc}
\hline & \multicolumn{7}{c}{ Concentration (FW) } \\
\cline { 2 - 9 } Leaf & $\mathbf{0 \%}$ & $\mathbf{0 . 2 5 \%}$ & $\mathbf{0 . 5 \%}$ & $\mathbf{1 \%}$ & $\mathbf{2 \%}$ & $\mathbf{4 \%}$ & $\mathbf{8 \%}$ & Mean \\
\cline { 2 - 9 } & $16.94 \mathrm{bc}$ & $20.83 \mathrm{a}$ & $22.50 \mathrm{a}$ & $21.33 \mathrm{ab}$ & $19.72 \mathrm{a}$ & $13.06 \mathrm{c}$ & $13.61 \mathrm{~cd}$ & $16.93 \mathrm{a}$ \\
Stem & $14.30 \mathrm{~cd}$ & $14.5 \mathrm{c}$ & $14.33 \mathrm{c}$ & $12.67 \mathrm{~cd}$ & $10.33 \mathrm{~d}$ & $8.17 \mathrm{de}$ & $6.28 \mathrm{e}$ & 10.35 \\
Fruit & $16.5 \mathrm{bc}$ & $14.5 \mathrm{c}$ & $14.66 \mathrm{c}$ & $11.06 \mathrm{~d}$ & $14.50 \mathrm{c}$ & $18.89 \mathrm{~b}$ & $16.94 \mathrm{bc}$ & $15.58 \mathrm{a}$ \\
Mean & $15.91 \mathrm{~b}$ & $16.61 \mathrm{a}$ & $17.16 \mathrm{a}$ & $15.02 \mathrm{~b}$ & $14.85 \mathrm{~b}$ & $13.37 \mathrm{c}$ & $12.28 \mathrm{~d}$ & \\
\hline
\end{tabular}


Table 8: Dry weight of $E$. cruss-galli as influenced by different concentration of different plant parts of $P$. somniferum aqueous extracts

\begin{tabular}{ccccccccc}
\hline Plant Parts & \multicolumn{7}{c}{ Concentration (DW) } \\
\cline { 2 - 9 } Leaf & $\mathbf{0 \%}$ & $\mathbf{0 . 2 5 \%}$ & $\mathbf{0 . 5} \%$ & $\mathbf{1 \%}$ & $\mathbf{2 \%}$ & $\mathbf{4 \%}$ & $\mathbf{8 \%}$ & Mean \\
\cline { 2 - 9 } Stem & $5.48 a$ & $5.25 a$ & $6.75 a$ & $5.69 a$ & $4.75 a$ & $4.33 a$ & $1.92 a$ & $4.43 a$ \\
& $7.50 a$ & $8.17 a$ & $7.00 a$ & $5.33 a$ & $4.50 a$ & $2.13 a$ & $1.00 a$ & $4.09 a$ \\
Fruit & $3.66 a$ & $3.87 a$ & $3.40 a$ & $3.70 a$ & $2.83 a$ & $4.04 a$ & $1.64 a$ & $3.18 a$ \\
Mean & $5.55 a$ & $4.47 a$ & $5.72 a$ & $4.91 a$ & $4.03 a$ & $3.50 a$ & $1.52 a$ & \\
\hline
\end{tabular}
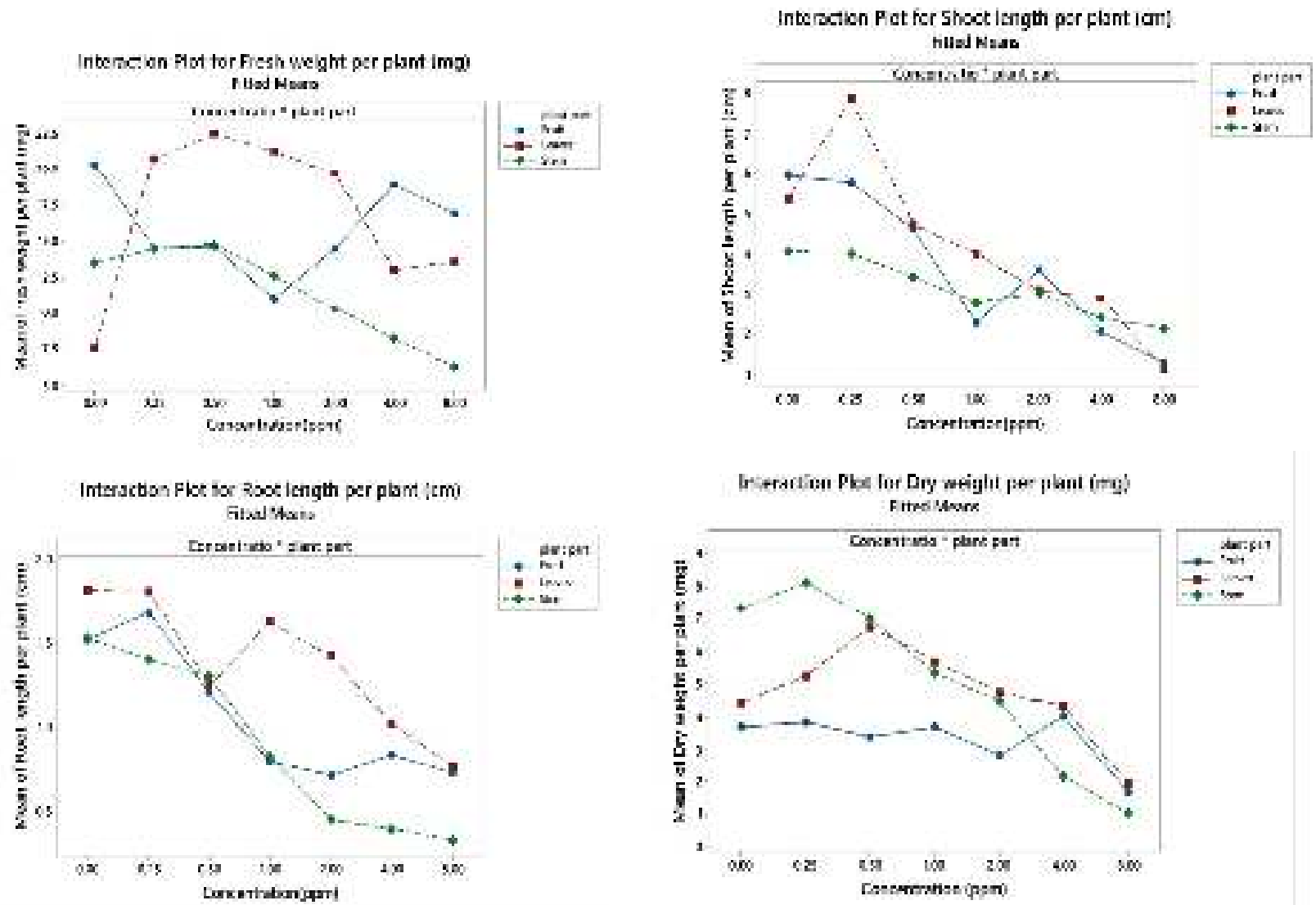

Figure 1: Interaction between treatment means of shoot length, root length, fresh weight, and dry weight of $E$. cruss-galliunder the influence of aqueous extracts of different parts of Papaver somniferum 


\section{References:}

Ahmad, A., Z. A. Cheema and R. Ahmad. 2000. Evaluation of sorghum as natural weed inhibitor in maize. $J$. Anim. Plant Sci., 10(1):141-146.

Alam, S. M. and E. Islam. 2002. Effect of aqueous extract of leaf, stem and root of nettle leaf gosse foot on germination and seedling growth of rice. Paki. J. Seed Techno,2(1): 4751.

Anjum T. and R. Bajwa. 2005. A bioactive annuionone from sunflower leaves. Phytochem. 66(1): 1919-1921.

Anjum, T., R. Bajwa and A. Javaid. 2005. Biological Control of Parthenium I: Effect of Imperata cylindrica on distribution, germination and seedling growth of Parthenium hysterophorus L. Int. J. Agric. Biol, 7(1):448-450.

Anonymous. 2005. Weed Science Society of Pakistan. wssp.org.pk

Baber, B. H., A. Tanveer, A. Aziz, M. M. Javaid, M. Tahir, M. Sibtain and $Z$. Pacanoski. 2009. Phytotoxic influences of Asphodelus tenuifolius Cav (wild onion) on germination and seedling growth of wheat. Allelopathy J., 24(2): 341-350.

Bajwa, A. A. 2014. Sustainable weed management in conservation agriculture. Crop Protec., 65(1):105113.

Bhowmik, P. C. 2003. Challenges and opportunities in implementing allelopathy for natural weed management. Crop prot., 22(4): 661671.

Cheema, Z. A., Asim, M., \& Khaliq, A. 2000. Sorghum allelopathy for weed control in cotton (Gossypium arboreum L.). Int. J. Agric. Biol., 2(1): 37-41.

Cheema, Z. A., S. Hussain and A. Khaliq. 2003. Efficacy of sorgaab in combination with Allelopathic water extracts and reduced rates of pendimethalin for weed control in mungbean (Vigna radiata L.). Indus. J. Plant Sci., 2(1): 21-25.

Chung, I. M., J. T. Kim and S. H. Kim. 2006. Evaluation of allelopathic potential and quantification of momilactone A, B from rice hull extracts and assessment of inhibitory bioactivity on paddy field weeds. $J$. agri. and food chem., 54(7): 25272536.

Cirujeda, A., J. Recasens, J. Torraand, A. Taberner. 2008. A germination study of herbicide-resistant field poppies in Spain. Agro. Sust. Devel., 28(2): 207220.

Coolbear P., A. Francis and D. Grierson. 1984. The effect of low temperature pre-sowing treatment on the germination performance and membrane integrity of artificially aged tomato seeds. J. Exp. Bot., 35: 16091617.

Ellis R.A. and E.H. Roberts. 1981. The quantification of aging and survival in orthodox seeds. Seed Sci. Technol. 9: 373-409.

Ferreira, M. I. and C. F. Reinhardt. 2010. Field assessment of crop residues for allelopathic effects on both crops and weeds. Agro. J., 102(6): 1593-1600.

Gallandt, E. R., and J. Weiner. 2001. Crop-weed competition. Els, 1-9.

Ghafarbi, S. P., S. Hassannejad and R. Lotfi. 2012. Allelopathic effects of wheat seed extracts on seed and seedling growth of eight selected weed species. Int. J. Agri. Crop Sci., 4(19): 1452-1457.

Ghodake, S. D., M. D Jagtap and M. B. Kanade. 2012. Allelopathic effect of three Euphorbia species on seed germination and seedling growth of wheat. Ann. Bio. Rese, 3(10):48014803.

Jabran, K., G. Mahajan, V. Sardana, and B. S. Chauhan. 2015. Allelopathy for weed control in agricultural systems. Crop Prot., 72: 57-65.

Javaid, A., T. Anjum and R. Bajwa. 2005. Biological control of Parthenium II: Allelopathic effect of Desmostachya bipinnata on distribution and early seedling growth of Parthenium hysterophorus L. Int. J. Bio. Biotechnol., 2(2):459-463.

Kadioglu, I., Y. Yanar, and U. Asav. 2005. Allelopathic effects of weeds extracts 
against seed germination of some plants. J. Envir. Bio, 26(2):169-173.

Khaliq, A., A. Matloob, M. N. Mushtaq and F. Aslam. 2009. Inhibitory effects of sorghum and sunflower water extracts on germination and growth of Cichorium intybus L. Proceeding, 1st Asian Allelopathy Society (AAS), December, 18(22): 110-125.

Khan, R., M. A. Khan, Waqas, A. M. Khan, Z. Hussain, A. Khan and M. A. Raza. 2011. Allelopathic potential of Silybum marianum L. against the seed germination of edible legumes. Pak. J. Weed Sci. Rese., 17(3): 293-302.

Labanca, F., J. Ovesna, and L. Milella. 2018. Papaver somniferum L. taxonomy, uses and new insight in poppy alkaloid pathways. Phytochem. Reviews, 17(4): 853-871.

Macias, F. A., R. M. Varela, A. Torres, J. L. Galindo and J. M. Molinillo. 2002. Allelochemicals from sunflowers: chemistry, bioactivity and applications. In Chemical ecology of plants: allelopathy in aquatic and terrestrial ecosystems (pp. 73-87).

Melander, B., I. A. Rasmussen and P. Bàrberi. 2005. Integrating physical and cultural methods of weed control-examples from European research. Weed Sci., 53(3): 369-381.

Nadeem, M. A., B. A. Khan, S. Afzal, H. Abbas, M. K. Dar, M. E. Safdar, I. Hassan, M. Asif, M. Adnan, A. Aziz. 2020c. Allelopathic Influence of Poppy (Papaver somniferum L.) on Emergence and Initial Seedling Growth of Red Rice (Oryza punctata L.). Pak. J. Weed Sci. Res. 26(4): 381-392.

Nadeem, M. A., B. A. Khan, S. Anwar, H. Abbas, M. Yasin, R. Maqbool, M. M. Amin, A. Aziz, M. S. Hayyat, M. S. Javed. 2020d. Phytotoxic Effects of Sonchus Oleraceus on Emergence and Seedling Growth of Echinocloa crussgalli. Pak. J. Weed Sci. Res. 26(4): 433-446

Nadeem, M.A., B.A. Jan, S. Afzal, M.A. Khan, T. Abbas, M.M. Javaid, M.M. Amin, N. Farooq and A. Aziz. 2020a.
Effect of aqueous extract of Carthamus tinctorius $L$. on germination and initial seedling growth of Oryza punctata L. Pak. J. Weed Sci. Res., 26(3): 331-342.

Nadeem, M.A., B.A. Jan, S.Afzal, M.A. Khan, T. Abbas, M.M. Javaid, M.M. Amin, N.Farooq, A. Aziz. 2020a. Effect of aqueous extract of carthamus tinctorius I. Ongermination and initial seedling growth of oryza punctata L. Pak. J. Weed Sci. Res., 26(3): 331342.

Nadeem, M.A., B.A. Khan, S. Afzal, A. Aziz, R. Maqbool, M.M Amin, A. Aziz, A. Ali, M. Adnan and Durrishahwar. 2020b. Allelopathic Effects of aqueous extracts of Carthamus tinctorius L. on emergence and seedling growth of Echinochloa crus-galli L. Pak. J. Weed Sci. Res., 26(3): 365-379.

Nadeem, M.A., B.A. Khan, S. Afzal, A. Aziz, R. Maqbool, M.M Amin, A. Aziz, A. Ali, M. Adnan, Durrishahwar. 2020b. Allelopathic Effects of Aqueous Extracts of Carthamus tinctorius $L$. on Emergence and Seedling Growth of Echinochloa crus-galli L. Pak. J. Weed Sci. Res., 26(3): 365-379.

Nadeem, M.A., B.A. Khan, S. Anwar, A. Aziz, R. Maqbool, M.E. Safdar, M.M. Javaid, A.Aziz. 2021. Assessing the Allelopathic Potential of Milk Thistle (Sonchus oleraceus L.) On Germination and Seedling Growth of Red Rice (Oryza punctata Kotschy ex Steud.). Pak. J. Weed Sci. Res., 27 (1):1-12.

Ravlić, M., R. Baličević, M. Knežević and I. Ravlić. 2012. Allelopathic effect of scentless mayweed and field poppy on seed germination and initial growth of winter wheat and winter barley. Herbologia, 13(2), 1-7.

Rose, M. L., and S. Anitha. 2012. Effect of Euphorbia hirta L. extract on the germination and seedling growth of groundnut. Advance Biotechnol., 12(1):27-29.

Shad, R. A. 1987. Status of Weed Science activities in Pakistan. Prog. 
Skrzypek, E., P. Repka, A. StachurskaSwakon, B. Barabasz-Krasny and K. Mozdzen. 2015. Allelopathic effect of aqueous extracts from the leaves of peppermint (Mentha piperita L.) on selected physiological processes of common sunflower (Helianthus annuus L.). Notulae Botanicae Horti Agrobotanici Cluj-Napoca, 43(2): 335342.

Takao, L. K., J. P. N. Ribeiro, and M. I. S. Lima. 2011. Allelopathic effects of Ipomoea cairica (L.) Sweet on crop weeds. Acta Botanica Brasilica, 25(4): 858-864.

Turk, M. A. and A. R. M. Tawaha. 2002. Impact of seeding rate, seeding date, rate and method of phosphorus application in faba bean (Vicia faba L. minor) in the absence of moisture stress.Biotechnol. Agron. Soc. Environ., 6(3): 171-178. 